\title{
Playground injuries
}

\section{MacKay}

\section{Recent attempts to begin to address what we don't know}

l

n the current issue of Injury Prevention two studies examine aspects of playground safety. Nixon and colleagues examined frequency of use of play equipment in public schools and parks in Brisbane, Australia ${ }^{1}$ and Sherker et al present the development of a novel method to investigate physical risk factors for playground related arm fractures. ${ }^{2}$ These studies represent recent attempts to begin to address gaps in research that enhance the current state of knowledge about this important childhood injury issue. Addressing these gaps is vital to a comprehensive understanding and approach to the issue, which will ensure effective policy decisions and result in a reduction in playground injury.

So what do we know? Playground injury has been recognised as an important issue for some time. We know that playground injuries are common and represent an important cause of childhood injury in most countries in the developed world. ${ }^{3-12}$ We also know that the age group most affected are school age children, whose increased exposure to playground equipment at schools, public parks, and back yards affects their risk. $^{7813-21}$ Thankfully, although reasonably common, most playground related injuries are not serious enough to cause permanent disability and fatal incidents are rare ${ }^{22-27}$ We know that the most common cause of playground injuries are falls from equipment (for example, climbers, monkey bars, slides). However, injury also results when children are struck by moving objects (for example, swings) or strangle either through head entrapment or as the result of clothing caught in equipment. ${ }^{34913-162022-41}$ The rare playground fatalities have for the most part been the result of asphyxiation secondary to strangulation, ${ }^{1322-27}$ while overall, the most common injuries seen in emergency departments are fractures and dislocations, most often the result of falls from equipment. ${ }^{341539}$ Estimates from hospitalisations have suggested that about $5 \%$ of children seen in the emergency department are admitted, the remainder being treated in the ambulatory setting and released. ${ }^{89}$

Of non-fatal injuries involving playground equipment, the most serious relate to the height of equipment (swings, slides, and climbers). While there is no consensus on safe heights, unsafe equipment height estimates range from 1.5 to 4.0 metres. ${ }^{21} 34-3638404243$ Height of equipment also has direct implications for type and depth of surfacing underlying playground equipment. Studies examining this issue find that the type and depth of surfacing at most playgrounds are inadequate (related to installation and maintenance). ${ }^{20} 38414244-48$ Attempts to address these issues have involved setting standards for playground equipment and landing surfaces. Equipment standards vary internationally ${ }^{43}$ 49-52 and their implementation and enforcement have not been rigorously evaluated. However, evidence from case-control studies conducted in a number of countries suggests that children are at higher risk from equipment that does not meet existing standards. Specifically, having an appropriate landing surface lowers the risk of injury in the event of a fall, as does compliance with a depth standard for the specified landing material. ${ }^{15} 35363840$

Despite this evidence, many playground structures do not meet current standards. $^{20} 38414244-48$ The challenge of implementation and enforcement of standards is further complicated by the fact that playground equipment can be under the jurisdiction of schools and day care facilities or, in the case of playgrounds in public parks, municipal or state/provincial governments. Playground equipment can also be found on private land, as in the case of backyards or campgrounds. Thus, while manufacturers do for the most part now build equipment for public play spaces that meet current standards, correct installation and maintenance are typically not enforced. Further, there are issues of old equipment not being modified to meet current standards and in most countries no standard exists for playground equipment sold to private home owners. Even in settings where policy requiring adherence to standards has been established, little attempt has been made to evaluate the impact of these policies. For example in Ontario, Canada, childcare facilities licensed by the Ministry of Community and Social Services are required to ensure that their outdoor play spaces meet the Canadian voluntary standard as part of licensing requirements (personal communication). The impact of this strategy on playground injury has yet to be evaluated.

Beyond descriptive epidemiological studies examining the magnitude of the issue and exploring risk factors, there have been few attempts to evaluate strategies to prevent playground injuries. ${ }^{53-61}$ Of the nine studies found, two studied engineering strategies related to landing surface ${ }^{5658}$ and seven examined educational approaches. ${ }^{53-55} 57$ 59-61 Only three used rigorously controlled designs. ${ }^{56581}$ None of the studies appear to have broadly influenced practice.

What don't we know? At the 6th World Conference in Montreal in May 2002 world experts on playground injuries met to discuss the current state of knowledge and, perhaps more importantly, the gaps in that knowledge. Important gaps identified included the unknown efficacy and effectiveness of interventions such as equipment and landing surface standards, policy/ regulation requiring adherence to said standards, signage, caregiver supervision, and equipment and surface maintenance by those responsible for playgrounds. While risk analyses suggest these strategies may play an important part in reducing playground injury, they have yet to be rigorously evaluated. However, further discussion suggested that evaluation of proposed intervention strategies was likely to be hampered by other knowledge gaps that result in an incomplete understanding of the playground injury issue. These gaps include information on body part specific risk factors and parameters (for example, arm fracture versus head injury), age specific risk factors (toddler versus school age), and exposure data.

A better understanding of body part or age specific risk factors will allow more focused interventions on injuries that are more common and/or costly to treat, and ultimately may serve to inform the enhancement of current playground safety standards. However, efforts in this area are currently impeded by a lack of validated measurement tools to quantify body part specific physical risk factors (for example, current playground impact tests have limited generalisability to body parts other than head injury) or issues around caregiver supervision. Sherker et al begin to address the former by examining methods to quantify equipment height and surface impact characteristics for arm fractures. ${ }^{2}$ These measurement tools and the information produced are vital to achieve a better understanding of risk, the design of more effective interventions, and evaluation of the cost benefit of the various strategies used.

As with many areas of injury prevention, there is also a lack of good exposure data. Most studies to date have reported 
population rates of playground injury, which likely underestimate overall or age specific injury rates, but may overestimate equipment specific rates. Few attempts have been made to go beyond this to examine playground use (for example, number of children/playground/week) or even more specifically equipment use (for example, number of children/ specific piece of equipment/hour). Nixon et al, in this issue, have attempted to quantify specific estimates of injury risk for different pieces of equipment in playgrounds in Brisbane. ${ }^{1}$ This study begins to fill an important gap that will allow prevention practitioners to determine the relative risk of specific pieces of playground equipment, thereby providing more accurate information to policy makers. The importance of addressing this gap cannot be underestimated, as exemplified by Nixon et al who conclude that their findings suggest that the economic costs of modifications and any resultant reduction in challenging play opportunities may outweigh the benefit of further injury reduction strategies in that community.

Play is an important part of healthy development of children and playground equipment serves as one tool with respect to that development. The public accept that play and injury resulting from play are part of childhood and this in and of itself results in additional challenge for those working to prevent these injuries. Both public education and recommendations to decision makers setting policy for design, installation, and maintenance of playground structures will be greatly enhanced if current gaps in understanding of risk and knowledge of effective prevention strategies are filled. We also need to know how effective vigorous enforcement of existing regulations is likely to be. Much could be learned by cross country comparisons. Meeting these challenges as an international community will ensure that safe and challenging playgrounds are possible.

Injury Prevention 2003;9:194-196

\section{Author's affiliation}

M MacKay, Children's Hospital of Eastern Ontario, Ottawa, Canada

Correspondence to: Ms MacKay; mmackay@cheo.on.ca

\section{REFERENCES}

1 Nixon JW, Acton $\mathrm{CHC}$, Wallis B, et al. Injury and frequency of use of playground equipment in public schools and parks in equipment in public schools and parks in
Brisbane, Australia. Inj Prev 2003;9:210-13.

2 Sherker S, Ozanne-Smith J, Rechnitzer G, et al. Development of a multidisciplinary method to determine risk factors for arm fractures in falls from playground equipment. Inj Prev 2003:9.279-83.

3 Illingworth C, Brennan P, Jay A, et al. 200 injuries caused by playground equipment BM 1975;iv:332-4.
4 Langley JD, Silva PA, Williams SM. Primary school accidents. N Z Med J 1981:94:336-9.

5 Sheps SB, Evans GD. Epidemiology of school injuries: a 2-year experience in a municipal health department. Pediatric 1987;79:69-75

6 Kazar G, Ihasz M, Kosa J, et al. [Childhood accidents] [Hungarian]. Orvosi Hetilap 1992:133:1937-43.

7 Bijur PE, Trumble A, Harel Y, et al. Sports and recreation injuries in US children and adolescents. Arch Pediatr Adolesc Med 1995; 149: 1009-16.

8 Kosmala $M$. [The analysis of frequency, causes and consequences of accidents on children's playgrounds] [Polish]. Pediatr Pol 1996;71:143-52.

9 Anonymous. Leads from the MMWR. Playground-related injuries in preschool-aged children-United States, 1983-1987. JAMA 1988;260:2799-800

10 Stark C, Wright J, Lee J, Watt L. Two years of school injuries in a Scottish education sub-division. Public Health 1996;110:22935

11 Linblad BE, Mikkelsen SS. [Playground accidents - fractures in the hip region [Danish]. Ugeskr Laeger 1991;153:1065-6.

12 Chalmers DJ, Langley JD. Epidemiology of playground equipment injuries resulting in hospitalization. J Paediatr Child Health 1990:26:329-34.

13 MacKellar A. Head injuries in children and implications for their prevention. J Pediatr Surg 1989;24:577-9

14 Mott A, Evans R, Rolfe K, et al. Patterns of injuries to children on public playgrounds. Arch Dis Child 1994:71:328-30.

15 Mowat DL, Wang F, Pickett W, et al. A case-control study of risk factors for playground injuries among children in Kingston and area. Inj Prev 1998;4:39-43.

16 Solheim K. [When children fall] [Norwegian]. Tidsskr Nor Laegeforen 1998:118:2481-2.

17 Bienefeld M, Pickett W, Carr PA. A descriptive study of childhood injuries in Kingston, Ontario, using data from a computerized injury surveillance system. Chronic Diseases in Canada 1996:17:21-7.

18 Coppens NM, Koziara DM. Children's perceptions concerning school injuries. Journal perceptions concerning school inju

19 Hopkins RS. Consumer product-related injuries in Athens, Ohio, 1980-85: assessment of emergency room-based surveillance. Am J Prev Med 1989;5:104-12.

20 Oliver TI, McFarlane JP, Haigh JC, et al. Playground equipment and accidents. Australian Paediatric Journal Australian Paediati

21 Pickett W, Carr PA, Mowat DL, et al. Playground equipment hazards and associated injuries in Kingston and area. Can J Public Health 1996;87:237-9.

22 Drago DA, Winston FK, Baker SP. Clothing drawstring entrapment in playground slides and school buses. Contributing factors and potential interventions. Arch Pediatr Adolesc Med 1997;151:72-7.

23 Feldman KW, Simms RJ. Strangulation in childhood: epidemiology and clinical course. Pediatrics 1980;65:1079-85.

24 Health Canada. For the safety of Canadian children and youth: from injury data to preventive measures. Ottawa, ON: Health Canada, 1997: chapter 12

25 Mack MG, Hudson S, Thompson D. A descriptive analysis of children's playground injuries in the United States 1990-4. Inj Prev 1997; 3:100-3.

26 Nixon J, Pearn J. Death during play: a study of playground and recreation deaths in children. BN 1981;283:410.

27 Petruk J, Shields E, Cummings GE, et al. Fatal asphyxiations in children involving drawstrings on clothing. Can Med Assoc J 1996; 155:1417-9.

28 Kotch JB, Chalmers DJ, Langley JD, et al. Child day care and home injuries involving playground equipment. J Paediatr Child Health 1993;29:222-7.
29 Langley JD, Cecchi J, Silva PA. Injuries in the tenth and eleventh years of life. Australian Paediatric Journal 1987:23:35-9.

30 Langley JD, Chalmers D, Collins B. Unintentional injuries to students at school. J Paediatr Child Health 1990;26:323-8.

31 Leung A, Robson W, Lim S, et al. Playground safety. J R Soc Health 1993;113:320-3.

32 Ball DJ, King KL. Playground injuries: a scientific appraisal of popular concerns. $J R$ Soc Health 1991:111:134-7.

33 Boyce WT, Sobolewski S, Sprunger LW, et al. Playground equipment injuries in a large, urban school district. Am J Public Health 1984;74:984-6.

34 Buck D. Safe on playgrounds? The nature and causes of children's playground accidents and opportunities for prevention. Public Health 1988; 102:603-11.

35 Chalmers DJ, Marshall SW, Langley JD, et al. Height and surfacing as risk factors for injury in falls from playground equipment: a case-control study. Inj Prev 1996;2:98-104.

36 Laforest $S$, Robitaille $Y$, Lesage $D$, et al. Surface characteristics, equipment height, and the occurrence and severity of playground injuries. Inj Prev 2001;7:35-40.

37 Lenaway DD, Ambler AG, Beaudoin DE. The epidemiology of school-related injuries: new perspectives. Am J Prev Med 1992;8:193-8.

38 Macarthur C, Hu X, Wesson DE, et al. Risk factors for severe injury associated with falls from playground equipment. Accid Anal Prev 2000;32:377-82.

39 Mack MG, Thompson D, Hudson S. Playground injuries in the 90s. Parks and Recreation 1998;33:88-95.

40 Mott A, Rolfe K, James R, et al. Safety of surfaces and equipment for children in playgrounds. Lancet 1997;349:1874-6.

41 Sacks JJ, Holt KW, Holmgreen P, et al. Playground hazards in Atlanta child care centers. Am J Public Health 1990;80:986-8.

42 Susnik S. Safety investigation of public playground equipment in the city of Toronto. Environmental Health Review 1995(summer):51-6.

43 Comité Européen de Normalisation. CEN 1177: impact absorbing playground surfacing - safety requirements and test methods. Brussels: Comité Européen de Normalisation, 1997.

44 Bond MT, Peck MG. The risk of childhood injury on Boston's playground equipment and surfaces. Am J Public Health 1993;83:731-3.

45 Langley JD, Crosado B. Two safety aspects of public playground climbing equipment. NZ Med J 1984;97:404-6.

46 Lesage D, Robitaille Y, Dorval D, et al. Does playground equipment conform to the Canadian standard? Can J Public Health 1995:86:279-83.

47 Ridenour M. Elementary school playgrounds: safe play area or inherent dangers. Percept Mot Skills 1987;64:447-51.

48 Rivers RP, Boyd RD, Baderman H. Falls from equipment as a cause of playground injury. Community Health 1978:9:178-9.

49 American Society for Testing Material. ASTM F1292 standard specification for impact attenuation of surface systems under and around playground equipment. West Conshohocken, PA: ASTM, 1991.

50 Standards Australia/NewZealand. AS/NZS 4422 Playground

surfacing-specifications, requirements and test methods. Sydney: Standards Australia/New Zealand, 1996.

51 Standards Australia. AS 1924-1: Playground equipment for parks, schools and domestic use-general requirements. Sydney: Standards Australia, 1981.

52 Canadian Standards Association International. CAN/CSA Z614-98: Childrens playspaces and equipment. Toronto: Canadian Standards Association International, 1998

53 Fisher L, Harris G, VanBurn J, et al. Assessment of a pilot child playground injury prevention project in New York state. Am J Public Health 1980;70:1000-2.

54 Laraque D, Barlow B, Davidson L, et al. The Central Harlem playground injury prevention 
project: a model for change. Am J Public Health 1994:84:1691-2.

55 Laraque D, Barlow B, Durkin $M$, et al. Injury prevention in an urban setting: challenges and successes. Bull N Y Acad Med 1995; 72:16-30

56 Lewis LM, Naunheim R, Standeven J, et al. Quantitation of impact attenuation of different playground surfaces under various environmental conditions using a tri-axial accelerometer. J Trauma 1993:35:932-5.
57 McEvoy M, Montana B, Panettieri M. A nursing intervention to ensure a safe playground environment. Journal of Pediatric playground environment. Journal

58 Robinovitch SN, Chiu J. Surface stiffness affects impact force during a fall on the outstretched hand. J Orthop Res 1998; 16:309-13.

59 Roseveare CA, Brown JM, Mclntosh JMB, et al. An intervention to reduce playground equipment hazards. Inj Prev 1999;5:124-8.
60 Sacks JJ, Brantley M, Holmgreen $P$, et al. Evaluation of an intervention to reduce playground hazards in Atlanta child-care centers. Am J Public Health 1992;82:429-31.

61 Sibert JR, Mott A, Rolfe K, et al. Preventing injuries in public playgrounds through partnership between health services and local authority: community intervention study. BM 1999:318: 1595.

\section{LACUNAE}

\section{Speed humps cost lives}

aramedics are warning that speed humps on London streets are killing hundreds of people a year by increasing ambulance response times. Sigurd Reinton, chairman of the London Ambulance Service, claimed in February that more lives are being lost through delays caused by speed humps and other calming measures than are saved by them.

"The situation is about more than road humps-our ambulances also have to slow down for chicanes and width barriers, often to walking pace", he said. "The fact that side streets have been shut off also has an impact as we then get caught up in the increased traffic on other routes.

"There is no doubt that the policies are well-intentioned, but I feel that the introduction of congestion charging offers an ideal opportunity to review their effectiveness".

Research in Boulder, Colorado, supports Reinton's claims. It suggests that for every life saved by traffic calming as many as 85 people may die because emergency vehicles are being held up. The report found response times are typically extended by $14 \%$ by speed reduction measures.

Cardiac arrests were of particular concern in the study: $90 \%$ of victims survive if treated within two minutes, though the rate falls to just $10 \%$ if they go untreated for six minutes. London has particularly low survival rates: among the 8000 people who suffer arrests each year only $2 \%$ of the most serious cases are revived.

The ambulance service calculates that each of the capital's 20 000-30 000 humps can add 15 seconds to a journey, with each minute's delay responsible for a $10 \%$ reduction in survival rates for cardiac arrest patients. Reinton says even the strictest traffic calming could reduce London road deaths by only another 100 a year, while his crews could save up to 800 more lives annually if calming measures did not delay them.

Emergency services chiefs have also previously criticised councils for introducing speed humps without any apparent consideration of their adverse effects. Although there are no signs of London ambulance crews claiming injuries as a result of speed humps, two firefighters in Sacramento, California, suffered spinal injuries in separate incidents when they hit their heads on the cab roof as their vehicle went over a hump. One was forced to take early retirement, the other was permanently disabled.

Humps have come in for criticism for other reasons, too. Although the official Department for Transport line is that they can increase car emissions by between $1 \%$ and $60 \%$, Austrian researchers found exhaust pollution can soar 10 -fold as drivers accelerate away from humps.

Transport for London (TfL) said it understood Reinton's concerns but did everything it could to strike the correct balance. "We give great consideration to balancing the needs of road users and pedestrians", said Derek Turner, managing director of street management for TfL. "Traffic calming measures should only be installed where it is necessary to reduce casualties" (based on a report in The Times (London), February 2003; submitted by Barry Pless). 